\title{
Understanding Reasons for Nonadherence to Medications in a Medicare Part D Beneficiary Sample
}

\author{
Ana L. Hincapie, PhD; Ann M. Taylor, MPH, MCHES;
}

Kevin P. Boesen, PharmD; and Terri Warholak, RPh, PhD

\begin{abstract}
BACKGROUND: Poor medication adherence is a predictor of poor health outcomes, especially in populations with chronic diseases. Although several self-reported measures of medication adherence exist, the scope of each is limited.

OBJECTIVE: To identify barriers to medication adherence in order to facilitate effective delivery of telephone-based medication therapy management (MTM) services to beneficiaries of contracted Medicare Part D plans.

METHODS: This study used a cross-sectional telephone-based questionnaire designed to elicit reasons for low medication adherence. Patients were eligible to participate if they were identified as nonadherent for an antilipidemic, antihypertensive, or antidiabetic agent. Nonadherence was defined as less than $80 \%$ of proportion of days covered (PDC). The questionnaire included 17 items pertaining to medication use and 3 demographic items. Data were collected between September 2012 and February 2013. Data analyses included descriptive statistics and Rasch analyses.
\end{abstract}

RESULTS: A total of 124 patients participated in the telephone survey. Of those completing the survey, the majority were patients (97.6\%); only 3 surveys $(2.4 \%)$ were completed by caregivers. The sample population had a mean age of 69.8 years $(S D=9.9)$, and more than half of participants $(60.4 \%)$ were female. Nineteen percent of respondents received their medications by mail. Medication nonadherence generated alerts mostly associated with antilipidemic agents $(n=50,40.3 \%)$, followed by antihypertensive drugs $(n=36,29.0 \%)$, and antidiabetic medications $(n=23,18.5 \%)$. The response categories for medication belief items were collapsed from 4 to 3 categories to achieve acceptable Rasch model fit (to fit the model and approximate interval level data). Ten percent of participants reported having medications prescribed either that they did not get or that they obtained but did not use. Almost $30 \%$ of patients reported having medications prescribed that they started using but stopped. However, only $4 \%$ of patients reporting adherence issues were related to the alert triggering for chronic medications; $96 \%$ of reports were linked to unrelated medications that did not generate an alert. The most common reason cited for medication nonadherence was experiencing side effects.

CONCLUSIONS: Most participants reported positive beliefs about medications and did not report adherence issues related to those triggering alerts. MTM programs offer potential solutions to a number of barriers to medication adherence and a unique opportunity to raise awareness about the importance of medication adherence among members.

J Manag Care Spec Pharm. 2015;21(5):391-99

Copyright $\odot 2015$, Academy of Managed Care Pharmacy. All rights reserved.

\section{What is already known about this subject}

Medication nonadherence has far-reaching effects such as increased health care utilization and expenditures, poor health outcomes, and decreased quality of life.

Research shows that medication therapy management (MTM) services are effective in decreasing medication problems and hospital readmission rates.

\section{What this study adds}

Patients frequently are unable to recognize their own adherence issues, especially for chronic medications

Inconsistency between patient self-reported adherence information and Medicare claims data indicate potential educational and interventional opportunities for MTM providers.

T he Institute for Healthcare Improvement developed the triple aim of improving health care quality, improving overall health, and reducing per capita cost of health. ${ }^{1}$ The Centers for Medicare \& Medicaid Services (CMS) has adopted this triple aim, and it is fundamental in today's health care system. ${ }^{2}$ While systemwide changes are imminent, patients, as well as health care providers, decision makers, and organizations, face multiple challenges in creating a more efficient and effective system. In particular, medication nonadherence-when patients are unable or intentionally choose not to follow recommended health care regimens-is a real and complex problem. ${ }^{3,4}$ Medication nonadherence has such farreaching effects as increased health care utilization and expenditures, poor health outcomes, and decreased quality of life. ${ }^{5}$

Nonadherence is a dynamic, complicated issue. Lack of resources (financial, social, psychological, and emotional) impacts motivation for adherence. ${ }^{6-8}$ Other factors such as changes in physical, emotional, or mental status; isolation; and disability (e.g., sight and hearing $)^{9}$ may affect patient adherence as well. Patients also report frequent changes to medications, limited faith (confidence) in medications, anger or denial about the illness, and avoidance of adverse side effects as deterrents to medication adherence. ${ }^{9,10}$

Patients with multiple conditions are at an increased risk because research has demonstrated that adherence decreases as the number of medications increases. ${ }^{9}$ DiMatteo et al. (2002) 
found that only about half of patients with chronic conditions take their medicines routinely as directed. ${ }^{11}$ Most seniors have 1 or more chronic conditions that require multiple medications (polypharmacy). ${ }^{12}$ Cost-related nonadherence (CRN) presents another challenge. Despite initiation of the Medicare Part D program, one-eighth to one-third of all seniors report CRNrelated issues. ${ }^{13-16}$

Currently, some older adults receiving Medicare Part D benefits are eligible for medication therapy management (MTM) services such as counseling and education related to medication adherence. Research shows MTM services are effective in decreasing medication problems and hospital readmission rates. ${ }^{17-22}$ Additionally, pharmacist services (e.g., MTM and patient education) decrease hospital admissions (up to $30 \%$ ), ${ }^{23,24}$ emergency department visits (up to 24\%), ${ }^{24,25}$ and overall health care expenditures. ${ }^{26,27}$ Despite these efforts, $4 \%-40 \%$ of all Medicare beneficiaries are nonadherent to prescribed medication regimens. ${ }^{28,29}$

Several instruments measure medication adherence and patients' beliefs about their medications. ${ }^{30}$ Yet, to the authors' knowledge, none of these instruments considers an important factor: the effect of patients' pharmacy-related experiences (e.g., costs, convenience, access, use of mail-order) on medication adherence.

Surveying patients about their medication nonadherence may be uncomfortable for some individuals. Telephone interviews, commonly used in quantitative research, may allow participants to be relaxed and more able and willing to share sensitive information. ${ }^{31}$ To date, most of the adherence-related questionnaires are designed for mail, electronic, or face-toface, rather than telephone, administration. Moreover, visual analogue scales that have demonstrated valid results may not be appropriate for telephonic administration. ${ }^{30}$ Telephonic surveys allow participant contact despite geographically dispersed locations, are generally shorter in length, and take less time to administer than other types of survey methods (e.g., face-to-face interviews $)^{31}$; however, they require special scripts with skip patterns, brevity in the number of items, and formal training of interviewers to ensure consistency in administration and data. Yet, the advantages outweigh the disadvantages when collecting sensitive health-related information.

The purpose of this cross-sectional study was to identify barriers to medication adherence to facilitate effective delivery of telephone-based MTM services to beneficiaries of contracted Medicare Part D plans.

\section{Methods}

\section{Study Design and Target Population}

This study employed a cross-sectional design to elicit reasons for nonmedication adherence among contracted Medicare Part D beneficiaries receiving MTM services.
The sample population included Medicare Part D patients receiving MTM services from the Medication Management Center (MMC) at the University of Arizona. In order to participate, patients had to be members of organizations contracting with the MMC and nonadherent for an antilipidemic, antihypertensive, or antidiabetic agent. For this study, nonadherence was considered less than $80 \%$ of proportion of days covered (PDC) in a 180-day measurement period for prescription claims for the same medication or another medication in the respective therapeutic class. Purposive sampling was used to identify the sample population for this study. In particular, several chronic conditions were identified (hyperlipidemia, hypertension, and diabetes) that may require patients to take prescription medications. Among patients with these diagnoses, the investigators wanted to recruit nonadherent patients to investigate reasons why they were unable or unwilling to follow the prescribed regimens. Additional inclusion criteria for participation in this study were ability to speak English and to manage medications. If participants were not in charge of their medications, consent to contact their caregivers was obtained. Study participation required patients to spend additional time on the telephone to respond to the survey items after completing their originally scheduled MTM consultation. However, study participation was voluntary, and subjects did not receive compensation. The University of Arizona Institutional Review Board approved this study.

\section{Adherence Instrument}

A 20-item questionnaire was specifically designed for this study to explore reasons for medication nonadherence. The survey included items in open-ended, dichotomous, and multiple-choice formats. The items elicited information regarding the following: (a) medical conditions for taking prescription medications; (b) problems associated with obtaining prescriptions from a pharmacy or via mail order; (c) prescription medications and reasons for not obtaining prescriptions; (d) prescription medications and reasons for not using as prescribed; (e) reasons for starting and then stopping prescription medications; and (f) demographic information.

The initial open-ended item verified the medical conditions for which the beneficiary was taking prescription medications. A second open-ended item asked respondents to describe any problems encountered in obtaining their medications. Next, a dichotomous item asked whether subjects received their medications via mail order pharmacy. If participants responded affirmatively, they were asked if they encountered any problems obtaining their medications through this mechanism. The next set of dichotomous items were developed to distinguish between beneficiaries who never picked up their prescriptions, those who obtained their prescriptions but never used them, and those who started taking their medications but stopped during the previous 3 months. If a beneficiary responded 
affirmatively to any of these questions, the interviewer asked for identification of each medication and the reasons for (a) not obtaining, (b) obtaining and not taking, or (c) starting and then stopping the prescribed regimens. Finally, the instrument included 5 items to measure beneficiary beliefs about medications, and 4 items assessed participant demographic information. The items measuring medication beliefs were adapted from a previous survey (see Appendix, available in online article, for more details on the telephone survey), as brief instruments suitable for telephone administration were found in the literature. ${ }^{32} \mathrm{~A} 4$-point Likert scale was employed to measure participant disagreement or agreement with each statement in the Beliefs About Medication Use subscale ( 1 = strongly disagree; 2 =disagree; 3 =agree; $4=$ strongly agree). Prior to data collection, the questionnaire was pilot tested with 3 pharmacists initially and subsequently with 10 patients to ensure clarity and content validity. The questionnaire was revised accordingly after the pilot testing.

\section{Modified Beliefs About Medication Use Subscale: Rasch Analysis}

Rasch analyses were conducted to assess item validity and reliability of the Beliefs About Medication Use items. Infit and outfit mean-squares (MNSQ) statistics were used to determine the construct relevance of the items in the Beliefs About Medication Use subscale. Infit MNSQ statistic is sensitive to item difficulty and participant's ability, while outfit MNSQ is more sensitive to extreme responses. In this study, if an item infit was placed between 0.6 and 1.4 , it was considered to fit the model appropriately. Values below this range may indicate item redundancy, and values above this range might indicate multidimensionality. ${ }^{33}$ A difference of 0.5 logits or higher on the measured scale between adjacent items was deemed an important gap in item content. ${ }^{34}$ Rasch analyses were used to evaluate the 4-point Likert-type scale used to measure participant disagreement or agreement regarding beliefs about medications statements. The rating scale analysis requires (a) at least 10 observations per category (category frequency); (b) observations that distribute appropriately across categoriesthat is, the probability curve for each category should have its own peak; (c) average measures that advance monotonically with category; (d) outfit mean squares that are less than 2; (e) step calibrations that advance; (f) rating to measure coherence; and $(\mathrm{g})$ step difficulties advance greater than or equal to 1.4 logits and less than 5 logits. Finally, reliability of the subscale of participant beliefs about medications was assessed with the Rasch person separation and reliability indices, with values over 2 and 0.8 , respectively, considered as adequate. ${ }^{35}$ This study targeted a minimum sample of 100 participants to obtain robust parameter estimates of this subscale. ${ }^{33}$
TABLE 1 Participant Demographic Characteristics

\begin{tabular}{|c|c|c|}
\hline Demographic Characteristics, $\mathrm{N}=124$ & \multicolumn{2}{|c|}{ Frequency, $\mathrm{n}(\%)^{\mathrm{a}}$} \\
\hline \multicolumn{3}{|l|}{ Gender } \\
\hline Female & 75 & $(60.4)$ \\
\hline Male & 49 & $(39.5)$ \\
\hline \multicolumn{3}{|l|}{ Marital status } \\
\hline Married or partnered & 72 & $(58.0)$ \\
\hline Divorced or separated & 15 & $(12.1)$ \\
\hline Widowed & 24 & (19.3) \\
\hline Never married & 8 & $(6.4)$ \\
\hline Refused to answer or missing & 5 & $(4.0)$ \\
\hline \multicolumn{3}{|l|}{ Education } \\
\hline Less than high school & 18 & $(15.0)$ \\
\hline High school graduate or equivalent & 86 & (71.6) \\
\hline College graduate or postgraduate & 16 & $(13.3)$ \\
\hline \multicolumn{3}{|l|}{ Employment status } \\
\hline Employed & 10 & $(8.1)$ \\
\hline Retired or not working & 91 & $(74.5)$ \\
\hline Disabled & 21 & $(17.2)$ \\
\hline Antilipidemic medications triggering alerts & 53 & $(42.7)$ \\
\hline Simvastatin & 17 & $(13.7)$ \\
\hline Atorvastatin & 13 & $(10.5)$ \\
\hline Pravastatin & 8 & $(6.5)$ \\
\hline Rosuvastatin & 5 & $(4.0)$ \\
\hline Other antilipidemics & 10 & $(8.1)$ \\
\hline Antihypertensive medications triggering alerts & 43 & $(34.6)$ \\
\hline Lisinopril & 13 & $(10.5)$ \\
\hline Valsartan & 6 & $(4.8)$ \\
\hline Enalapril & 5 & $(4.0)$ \\
\hline Hydrochlorothiazide & 4 & $(3.2)$ \\
\hline Atenolol & 3 & $(2.4)$ \\
\hline Diltiazem & 3 & $(2.4)$ \\
\hline Other antihypertensives & 9 & $(7.3)$ \\
\hline Antidiabetic medications triggering alerts & 28 & $(22.5)$ \\
\hline Metformin & 14 & (11.3) \\
\hline Glimepiride & 8 & $(6.5)$ \\
\hline Other antidiabetics & 6 & (4.8) \\
\hline
\end{tabular}

\section{Data Collection and Analysis}

Two pharmacy students in their final year of pharmacy school conducted the survey interviews at the MMC with eligible patients. To ensure consistency in data collection procedures and reduce the potential for bias, both interviewers completed a formal training session conducted by the investigator (Boesen); additionally, the interviewers used a scripted survey with skip patterns.

The telephone questionnaire was administered after completion of the beneficiary's scheduled MTM consultation. Participation in the survey was voluntary. Initially, the trained interviewer determined if the beneficiary met the eligibility criteria. Next, the interviewer asked if the eligible beneficiary was interested in participating in the research study. If the beneficiary responded affirmatively, the interviewer followed the 
Understanding Reasons for Nonadherence to Medications in a Medicare Part D Beneficiary Sample

TABLE 2 Frequency of Participant Responses for Beliefs Regarding Medication

Use Items and Rasch Analysis Summary of Item Properties

\begin{tabular}{|c|c|c|c|c|c|c|c|}
\hline \multirow[b]{2}{*}{ Items } & \multicolumn{4}{|c|}{ Raw Data } & \multicolumn{3}{|c|}{ Rasch Fit Data ${ }^{a}$} \\
\hline & $\begin{array}{c}\text { Strongly } \\
\text { Disagree } \\
\text { n (\%) }\end{array}$ & $\begin{array}{c}\text { Disagree } \\
\text { n (\%) }\end{array}$ & $\begin{array}{l}\text { Agree } \\
\text { n (\%) }\end{array}$ & $\begin{array}{c}\text { Strongly } \\
\text { Agree } \\
\text { n (\%) }\end{array}$ & $\begin{array}{c}\text { Item } \\
\text { Measure } \\
\text { (SE) }\end{array}$ & $\begin{array}{c}\text { MNSQ } \\
\text { Infit }\end{array}$ & $\begin{array}{c}\text { MNSQ } \\
\text { Outfit }\end{array}$ \\
\hline I do not worry about the future problems of my medicines. & $20 \quad(16.5)$ & $31 \quad(25.6)$ & $50 \quad(41.3)$ & $20(16.5)$ & $1.23(0.15)$ & 1.27 & 1.26 \\
\hline I worry about taking medicines. & $43(35.5)$ & $41 \quad(33.8)$ & $25(20.6)$ & $12 \quad(9.9)$ & $0.41(0.15)$ & 1.07 & 1.08 \\
\hline I can live without my medications. & $59(48.7)$ & $43(35.5)$ & $14(11.5)$ & $5 \quad(4.1)$ & $-0.36(0.15)$ & 1.18 & 1.29 \\
\hline My medicines keep me healthy. & $2 \quad(1.6)$ & $6 \quad(5.0)$ & $56 \quad(47.0)$ & $55(46.2)$ & $-0.57(0.16)$ & 0.61 & 0.61 \\
\hline My medicines are easy to use. & $1 \quad(0.8)$ & $4 \quad(3.3)$ & $56 \quad(47.0)$ & $58(48.7)$ & $-0.71(0.16)$ & 0.84 & 0.90 \\
\hline
\end{tabular}

informed consent procedures and answered any questions. If the beneficiary was unable to respond to the survey items (e.g., knowledge deficit, physical/emotional limitations), the authorized caregiver was asked to participate on the beneficiary's behalf. For those choosing not to participate, the interviewer thanked the beneficiary and ended the call.

Prior to beginning the telephone survey, the trained interviewer identified the prescription medications, via pharmacy claims data, prescribed for the eligible beneficiary. The trained interviewer then proceeded to administer the survey, which took approximately 15 minutes to complete. The telephone interviews were conducted between September 2012 and February 2013.

Summary statistics were calculated for each of the questionnaire items using STATA 12 (Statacorp, College Station, TX). Rasch analyses were conducted using WINSTEPS version 3.71.0.1 (Winsteps.com, Queensland, Australia).

\section{Results}

\section{Patient Demographic Characteristics and Medication Use: Descriptive Statistics}

A total of 124 patients participated in the survey. Of those completing the telephone survey, the majority were patients (97.6\%); only 3 surveys (2.4\%) were completed by caregivers. The sample population had a mean age of 69.8 years (standard deviation $=9.9)$, and more than half of the participants $(60.4 \%)$ were female. More than half (58.0\%) of patients surveyed were married, while approximately three-quarters were retired or not working $(74.5 \%)$ and had completed a high school education (71.6\%; Table 1).

A small proportion of participants (19.0\%) received their medications by mail. Medication nonadherence, defined as a PDC lower that $80 \%$, generated alerts mostly associated with antilipidemic agents $(n=53,42.7 \%)$, followed by antihypertensive drugs $(n=43,34.6 \%)$ and antidiabetic medications $(\mathrm{n}=28,22.5 \%)$. Table 1 summarizes the most common medi- cations within each category. Only 5 respondents (4.0\%) selfreported medical conditions where prescription medications were used; these conditions included high cholesterol, diabetes, hypertension, hypothyroidism, and chronic obstructive pulmonary disease.

\section{Beliefs About Medication Use: Descriptive Statistics}

The majority (57.8\%) of participants indicated they did not worry about future problems with their medications, and nearly two-thirds (69.3\%) were not worried about taking medications. Four-fifths of participants (84.2\%) indicated they could not live without their medications, and the vast majority (93.2\%) either strongly agreed or agreed that their medicines keep them healthy. Most respondents (95.7\%) strongly agreed or agreed that their medications were "easy to use" (Table 2).

\section{Modified Beliefs About Medication Use Subscale: Rasch Analysis}

The functioning of the rating scale was examined. There were at least 10 observations per category. However, the frequency distribution (Figure 1) indicated that the "disagree" response option was problematic given that it failed to reach the 0.5 probability threshold of being selected. Collapsing the "strongly disagree" and "disagree" categories produced a better fit to the model (Table 3). Rasch analysis was also performed to assess the extent that each item in the scale contributed to the model fit. All items fell inside the acceptable Rasch model fit criteria (0.6-1.4 logits), indicating the absence of overfitting or misfitting items (Table 2). The hardest item to endorse by participants was "I do not worry about the future problems of my medicines," while the easiest item to endorse was "My medicines are easy to use." There was a significant content gap between the item "I do not worry about the future problems of my medicines" and "I worry about taking medicines," since the difference in logits of the item measures was greater than 0.5 (Table 2). Finally, the person reliability and person separation 


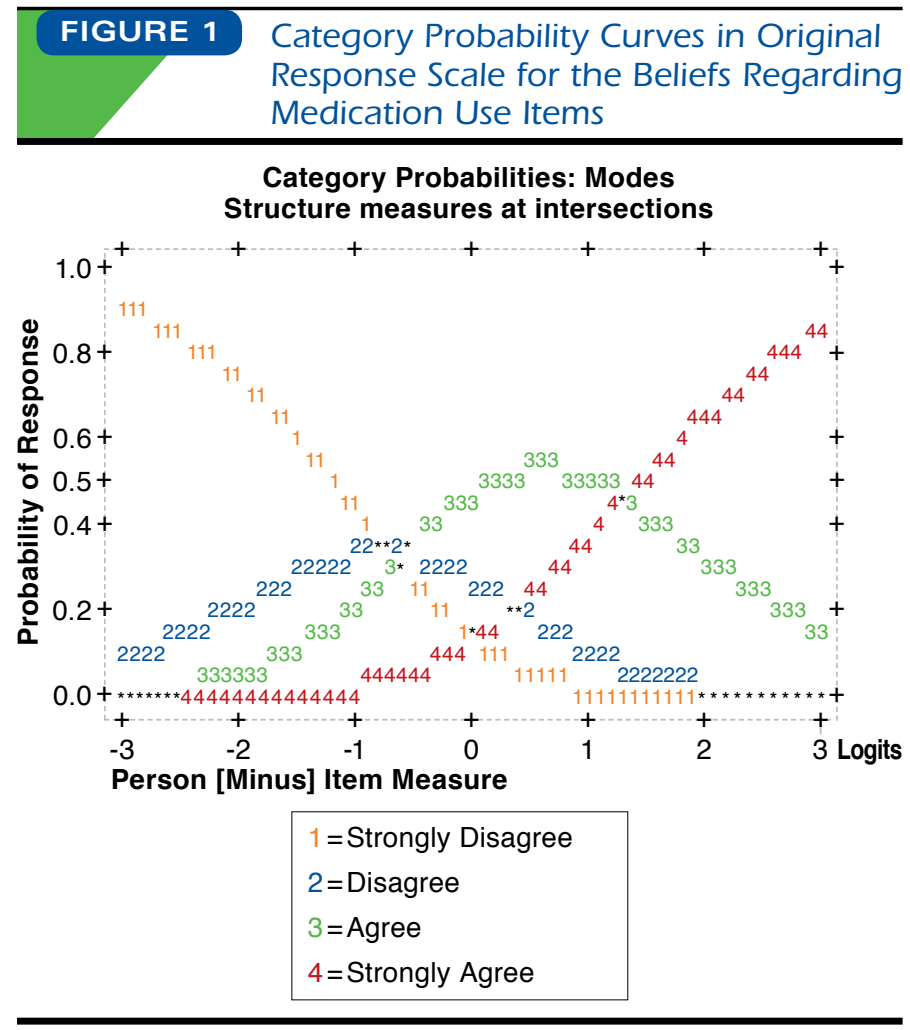

indices for the model were 0.46 and 0.90 , respectively. These indices fell below the accepted threshold values of 0.8 and 2 correspondingly, indicating that the subscale was not able to discriminate between different levels of respondents' beliefs about medications.

\section{Reasons for Medication Nonuse or Discontinuation: Descriptive Statistics and Qualitative Results}

Almost half ( $n=60,48.3 \%$ ) of all participants reported never obtaining, obtaining but not using, or starting but stopping prescribed medications. The most frequently cited reasons for not obtaining their prescribed medications $(n=12)$ were cost (25.0\%) and the pharmacy staff telling them the prescription was already picked up (16.7\%), followed by transportation, unavailability of medication, use of samples, and purchasing medications abroad (8.3\% for each reason). Two participants (16.7\% of respondents) provided no reason (Table 4).

Participants who obtained but did not use their medications $(\mathrm{n}=13)$ reported medication-related problems (38.5\%) most frequently, followed by non-necessity for condition (15.3\%) and felt better so did not need medicine (15.3\%). Four participants (30.7\%) provided no reason.

Participants who reported starting then stopping their medications $(n=35)$ cited these reasons most frequently: medication side effects (40.0\%), physician switched medication (34.3\%),

\begin{tabular}{l|c|c|c|c|c}
\hline TABLE 3 & $\begin{array}{l}\text { Summary of Category Structure of } \\
\text { the Collapsed Beliefs Regarding } \\
\text { Medication Use Scale }\end{array}$ \\
\hline $\begin{array}{l}\text { Category } \\
\text { Label }\end{array}$ & $\begin{array}{c}\text { Observed } \\
\text { Count } \\
\mathbf{n}(\%)\end{array}$ & $\begin{array}{c}\text { Average } \\
\text { Measure }\end{array}$ & $\begin{array}{c}\text { Infit } \\
\text { MNSQ }\end{array}$ & $\begin{array}{c}\text { Outfit } \\
\text { MNSQ }\end{array}$ & Threshold \\
\hline Disagree & $120(19.9)$ & -0.62 & 1.0 & 1.1 & - \\
\hline Agree & $246(40.9)$ & 0.2 & 0.9 & 0.8 & -0.91 \\
\hline Strongly agree & $235(39.1)$ & 1.3 & 0.9 & 1.0 & 0.91 \\
\hline MNSQ= mean square residuals.
\end{tabular}

and felt better so did not need medicine (11.4\%). Only 4\% of the medications identified by respondents as problematic corresponded to the medication triggering the alert based on the claims data. The medications that patients were referring to while answering the previously mentioned questions are presented in Table 4.

\section{Discussion}

This telephone study assessed beliefs and practical barriers to medication adherence. Most participants reported positive beliefs about medications and did not report adherence issues related to the triggering medications. It is encouraging that patients failed to report negative medication beliefs, especially since these viewpoints are difficult to change. However, every patient contacted was surveyed because the retrospective claims data indicated an adherence problem for a trigger medication (i.e., an antilipidemic, antihypertensive, or antidiabetic agent); yet, most did not seem to acknowledge their nonadherence.

Patients were identified based on their PDC. The PDC is a method of determining medication adherence endorsed by the Pharmacy Quality Alliance and the Centers for Medicare \& Medicaid Services ${ }^{36,37}$ PDC assesses the available days' supply of a medication across an interval of time; the previous 180 day interval was used for this study. Other adherence measures are available; however, the PDC was our preferred choice given our Medicare population. ${ }^{38}$ The data available to determine PDC included covered Medicare claims as well as any claims associated with any other gap coverage that the patients may have had.

Of interest in this study is the number of patients that, despite a PDC less than $80 \%$, failed to acknowledge their gap in adherence. A potential explanation is a gap in claims due to cash-paid prescriptions or even the use of medication samples. However, both of these gaps would have emerged during the structured medication reconciliation completed with the patient.

The most frequently cited reasons for not obtaining prescribed medications $(n=12)$ were cost $(25.0 \%)$ and the pharmacy staff saying that the prescription was already picked up (16.7\%), followed by transportation, unavailability of 
TABLE 4 Participant Reasons for Medication Nonuse and Cease of Use

\begin{tabular}{|c|c|c|}
\hline $\begin{array}{l}\text { Medications Prescribed: } \\
\text { Did Not Obtain } \\
n=12(9.6 \%)\end{array}$ & $\begin{array}{l}\text { Medications Prescribed: } \\
\text { Obtained Did Not Use } \\
n=13(10.4 \%)\end{array}$ & $\begin{array}{l}\text { Medications Prescribed: } \\
\text { Started Using but Stopped } \\
\mathbf{n}=35(28.2 \%)\end{array}$ \\
\hline $\begin{array}{l}\text { - Patient thought the medicine was not necessary } \\
\text { for the condition }(\mathrm{n}=1) \\
\text { - Patient thought medicine cost too much }(\mathrm{n}=3) \\
\text { - The prescription was not available—out of stock } \\
(\mathrm{n}=1) \\
\text { - Patient couldn't get to the pharmacy }(\mathrm{n}=1) \\
\text { - Patient used samples }(\mathrm{n}=1) \\
\text { - Pharmacy claimed prescription was already } \\
\text { picked up }(\mathrm{n}=2) \\
\text { - Patient bought medicines abroad }(\mathrm{n}=1) \\
\text { - Reason not stated }(\mathrm{n}=2)\end{array}$ & $\begin{array}{l}\text { - Patient thought the medicine was not necessary } \\
\text { for the condition }(n=2) \\
\text { - Patient has taken the medicine, and it gave } \\
\text { him/her problems }(n=5) \\
\text { - Patient felt better so didn't need medicine } \\
(n=2) \\
\text { - Reason not stated }(n=4)\end{array}$ & $\begin{array}{l}\text { - Patient thought the medicine was not necessary } \\
\text { for the condition }(n=1) \\
\text { - Patient thought medicine cost too much }(n=3) \\
\text { - Patient took the medicine and it gave him/her } \\
\text { problems-side effects }(n=14) \\
\text { - Patient felt better so didn't need medicine } \\
(n=4) \\
\text { - Physician switched the medication }(n=12) \\
\text { - Patient thought insurance stopped the medicine } \\
(n=1)\end{array}$ \\
\hline $\begin{array}{l}\text { Medications Self-Reported in this Category } \\
\text { - Acarbose, atorvastatin, furosemide, naproxen, } \\
\text { sitagliptin, oxycodone, others (unknown) }\end{array}$ & $\begin{array}{l}\text { Medications Self-Reported in this Category } \\
\text { - Insulin lispro, Clarithromycin, levalbuterol, } \\
\text { lorazempan, paroxetine, tramadol, ezetimibe, } \\
\text { glibenclamide, hydrocodone, phosphate binder, } \\
\text { tiotropium bromide, unidentified eye drops, } \\
\text { others (unknown) }\end{array}$ & $\begin{array}{l}\text { Medications Self-Reported in this Category } \\
\text { - Acarbose, celecoxib, cholestyramine, eye drops, } \\
\text { fluvastatin, furosemide, gabapentin, hydrochlo- } \\
\text { rothiazide, lisinopril, nitrofurantoin, oxymor- } \\
\text { phone, pravastatin, pramipexole, simvastatin, } \\
\text { sitagliptin, tiotropium bromide, tramadol, trazo- } \\
\text { done, zolpidem }\end{array}$ \\
\hline
\end{tabular}

medication, use of samples, and purchasing medications abroad ( $8.3 \%$ for each reason). Two participants (16.7\%) provided no reason (Table 4). This sample population reported nonadherence to newly prescribed medications that parallel findings from other published studies. ${ }^{39,40}$ Yet, pharmacists are in a unique position to help these patients overcome adherence-related barriers to improve health-related outcomes. ${ }^{38}$

There are several likely reasons why patients failed to acknowledge their nonadherence. It is possible that, for some patients, the adherence gaps were closer to the beginning of the 6-month measured interval, and they had recently become more adherent. However, it is more likely that a lack of knowledge existed relative to their own PDC. Also, patients in this study had a minimum of 8 chronic medications prescribed to treat a number of conditions. While it is feasible that they could adhere to most regimens, missing as few as 3 doses over a 2-week period would reduce the PDC for a specific medication below the adherence threshold. The complexity of managing multiple chronic illnesses is potentially too burdensome, especially without access to some type of personal support (e.g., caregiver, friend, or family member). Thus, patients may not notice their own gaps in therapy.

Patients did report adherence issues, albeit not for the triggering medications. Most of the medications were for treating short-term conditions or conditions where manifestation of symptoms was more evident for patients. It is possible that some respondents were hospitalized during the previous 180 days, thus, affecting their responses for multiple reasons (e.g., too sick to recall events, confusion about inpatient/outpatient medications). Further research is required to ascertain whether patient awareness and understanding of medication adherence is based on the acuity of medical conditions, which would affect the validity of self-reported medication adherence measurements routinely used in clinical practice.

Nonetheless, most of the reported barriers were practical in nature and easily resolved. For example, some patients cited lack of transportation for not obtaining their medications. Assisting patients with signing up for and obtaining prescriptions via mail order or home delivery by community pharmacies may provide a viable solution to the transportation issue. However, many patients cited cost as an issue for not obtaining their prescription medications. Making changes in health care policies to ensure affordable prescription medications for all patients is a much more complex issue. To address the cost issue, pharmacists can help these patients switch to a lowercost therapeutic alternative.

Participants who obtained but did not use their medications most frequently reported medication-related problems (38.5\%) for nonadherence. There are several potential opportunities to address this issue via existing MTM services. Improving communication between the primary care provider, pharmacist, and patient could help resolve this issue simply by prescribing an alternative medication with fewer side effects. Additionally, almost one-third (30.6\%) of participants cited non-necessity for condition and feeling better so did not need medicine as reasons for not taking their medications. These issues are also manageable as a component of a patient engagement/education program (MTM intervention) focusing on the importance of taking medications as prescribed for chronic conditions to prevent disease progression, treatment failure, and other more serious consequences. 
Participants who reported starting then stopping their medications most frequently cited medication side effects, physician switched medication, and felt better so did not need medicine. Again, these reasons for nonadherence may be addressed by MTM services. Pharmacists could recommend that the provider prescribe another equally effective alternative medication and educate the beneficiary about improving chronic disease prognosis and overall health.

Medication nonadherence is a serious problem with possible life-threatening consequences. As observed in this study, patients frequently are unable to recognize their own adherence issues, especially for chronic medications. Thus, it is imperative for MTM programs to first identify population-specific medication adherence barriers and subsequently offer more effective and efficient solutions. Additionally, these programs have a unique opportunity to raise awareness about the importance of medication adherence among their members. This would not only benefit patients, it would also enhance Medicare Part D plan performance on CMS medication adherence star ratings. ${ }^{41}$ Currently, CMS uses 3 medication adherence (Part D) performance measures: oral antidiabetic medications, antihypertensive agents (renin-angiotensin system antagonists), and cholesterol medications (statins). While these measures are important for Part D ratings, they also contribute to a health plan's Part $\mathrm{C}$ ratings for diabetes care (blood sugar and cholesterol control) and hypertension control. ${ }^{42}$ Thus, it is imperative that health care providers, pharmacists, health educators, and health care decision makers align themselves to develop effective policies and programs to improve patient adherence so as to reduce health care utilization and its associated costs.

The Rasch analyses results showed the need for combining 2 categories (strongly disagree and disagree) to fit the model, since 1 category (disagree) was rarely observed. This suggests that the 4-point rating scale functioned less than ideally in this sample population. There are multiple reasons that may explain why this occurred. It may have been difficult for participants to differentiate between the rating scale anchor of strongly disagree and disagree. In this case, using a rating scale with fewer points (i.e., 3 points) may work better. Alternatively, this study included a relatively small sample size; however, it is feasible that in a larger study sample the selection frequency of the disagree category would be higher, thus, eliminating the need to collapse these 2 categories. Additionally, participants had difficulty endorsing the item "I do not worry about the future problems of my medicines." Several explanations may account for this phenomenon. First, the use of double negative wording in the statement may have been confusing. Second, it is possible that participants were unable to foresee or may have not understood the potentials side effects of their medicines. The person separation and reliability indices were below accepted levels. This may be due, in part, to the small number of items in the subscale (5 items) or to the content of the items. Future iterations of this subscale are warranted prior to recommending it for use in other studies. Moreover, further analyses should consider avoiding use of double negative statements as well as inclusion of additional items, especially between the 2 items where a gap was observed.

\section{Limitations}

This study was subject to several limitations. First, this study used a cross-sectional design. This type of study design is advantageous given that it does not require follow-up so is less expensive and has a shorter implementation timeline. However, a disadvantage of a cross-sectional design is that it excludes the long-term follow-up needed to determine whether participant behaviors or actions are maintained or deteriorate over time.

Second, the authors recognize the small sample size is a study limitation and that the results are not generalizable to all Medicare Part D patients receiving MTM services. However, an advantage of the smaller sample size is that it enabled the researchers to gain some valuable insight into problems associated with medication adherence. These study results are encouraging and will serve to inform future projects with larger patient/beneficiary populations.

Third, another study limitation is response bias. Given that beneficiaries were asked about a sensitive matter with a negative connotation (nonadherence), it is plausible they may have underreported reasons for nonadherence to prescribed medication regimens. That is, beneficiaries may have only reported 1 reason for nonadherence when in actuality there were multiple reasons. Alternatively, they may have chosen to report a more socially desirable reason (e.g., cost) rather than a less desirable one (e.g., transportation). However, using a telephone survey method may have helped counteract response bias by providing a safe and more relaxed environment for beneficiaries to share sensitive information. ${ }^{31}$

\section{Conclusions}

This study identified reasons for medication nonadherence among a sample population of Medicare Part D beneficiaries receiving MTM services via a university-based medication management center. Most participants reported positive beliefs about medications and did not report adherence issues related to the triggering medications. MTM programs are in a unique position to raise awareness about the importance of medication adherence among their members. To remain at the forefront, MTM programs must offer potential solutions to a number of the barriers to medication adherence to improve patient health and safety. 


\section{Authors}

ANA L. HINCAPIE, PhD, is Assistant Professor, James L. Winkle College of Pharmacy, University of Cincinnati, Ohio. ANN M. TAYLOR, MPH, MCHES, is Program Manager, HOPE Center, and TERRI WARHOLAK, RPh, PhD is Associate Professor, College of Pharmacy, University of Arizona, Tucson. KEVIN P. BOESEN, PharmD is Chief Executive Officer, SinfoniRx, Tucson, Arizona.

AUTHOR CORRESPONDENCE: Ana L. Hincapie, Assistant Professor, James L. Winkle College of Pharmacy, University of Cincinnati, 3225 Eden Ave., Cincinnati, OH, 45267.

Tel.: 513.558.4177; E-mail: Ana.Hincapie@uc.edu.

\section{DISCLOSURES}

Kevin Boesen is employed by SinfoniaRx. The authors declare no other potential conflicts of interest.

Study concept and design were contributed by Warholak, Boesen, and Hincapie. Data were collected by Boesen and interpreted by Hincapie, Taylor, and Warholak. The manuscript was written by Hincapie and Taylor, with Warholak and Boesen taking the lead roles in revision, assisted by the other authors.

\section{ACKNOWLEDGMENTS}

The authors gratefully acknowledge the Medication Management Center at The University of Arizona.

\section{REFERENCES}

1. Berwick DM, Nolan TW, Whittington J. The triple aim: care, health, and cost. Health Aff (Millwood). 2008;27(3):759-69.

2. Medicare Advantage Quality Improvement Workgroup. Medicare Advantage and Medicare Prescription Drug Plan Quality Strategy: a framework for improving care for beneficiaries. Medicare Drug \& Health Plan Contract Administration Group. June 2012. Available at: http://www.cms.gov/ Medicare/Health-Plans/Medicare-Advantage-Quality-Improvement-Program/ Downloads/Quality_Strategy_061212.pdf. Accessed March 15, 2015.

3. Marcum ZA, Gellad WF. Medication adherence to multidrug regimens. Clin Geriatr Med. 2012;28(2):287-300.

4. Maher RL, Hanlon J, Hajjar ER. Clinical consequences of polypharmacy in elderly. Expert Opin Drug Saf. 2014;13(1):57-65.

5. Sokol MC, McGuigan KA, Verbrugge RR, Epstein RS. Impact of medication adherence on hospitalization risk and healthcare cost. Med Care. 2005;43(6):521-30.

6. Affleck G, Tennen H, Pfeiffer C, Fifield J. Appraisals of control and predictability in adapting to a chronic disease. J Pers Soc Psychol. 1987;53(2):273-79.

7. Becker MH. Psychosocial aspects of health-related behavior. In: Freeman HE, Levine S, Reeder LG, eds. Handbook of Medical Sociology. Englewood Cliffs, NJ: Prentice Hall; 1979:253-74.

8. Rickles NM. A multi-theoretical approach to linking medication adherence levels and the comparison of outcomes. Res Social Adm Pharm. 2010;6(1):49-62.

9. Vlasnik JJ, Aliotta SL, DeLor B. Medication adherence: factors influencing compliance with prescribed medication plans. Case Manager. 2005;16(2):47-51

10. Ho PM, Rumsfeld JS, Masoudi FA, et al. Effect of medication nonadherence on hospitalization and mortality among patients with diabetes mellitus. Arch Intern Med. 2006;166(17):1836-41.
11. DiMatteo MR, Giordani PJ, Lepper HS, Croghan TW. Patient adherence and medical treatment outcomes: a meta-analysis. Med Care. 2002:40(9):794-811.

12. Anderson G, Horvath J. The growing burden of chronic disease in America Public Health Rep. 2004;119(3):263-70. Available at: http://www.ncbi.nlm.nih. gov/pmc/articles/PMC1497638/pdf/15158105.pdf. Accessed March 30, 2015.

13. Piette JD, Heisler M, Wagner TH. Cost-related medication underuse among chronically ill adults: the treatments people forgo, how often, and who is at risk. Am J Public Health. 2004;94(10):1782-87.

14. Soumerai SB, Pierre-Jacques M, Zhang F, et al. Cost-related medication nonadherence among elderly and disabled medicare beneficiaries: a national survey 1 year before the medicare drug benefit. Arch Intern Med. 2006;166(17):1829-35.

15. Madden JM, Graves AJ, Zhang F, et al. Cost-related medication nonadherence and spending on basic needs following implementation of Medicare Part D. JAMA. 2008;299(16):1922-28.

16. Gellad WF, Haas JS, Safran DG. Race/ethnicity and nonadherence to prescription medications among seniors: results of a national study. J Gen Intern Med. 2007;22(11):1572-78.

17. Rozich J, Resar R. Medication safety: one organization's approach to the challenge. J Clin Outcomes Manage. 2001;8(10):27-34.

18. Vira T, Colquhoun M, Etchells E. Reconcilable differences: correcting medication errors at hospital admission and discharge. Qual Saf Health Care. 2006;15(2):122-26.

19. Nickerson A, MacKinnon NJ, Roberts N, Saulnier L. Drug-therapy problems, inconsistencies, and omissions during a medication reconciliation and seamless care service. Healthc Q. 2005;8(Spec No):65-72

20. Pronovost P, Weast B, Schwarz M, et al. Medication reconciliation: a practical tool to reduce the risk of medication errors. J Crit Care. 2003;18(4):201-05.

21. Rodehaver C, Fearing D. Medication reconciliation in acute care: ensuring an accurate drug regimen on admission and discharge. Jt Comm J Qual Patient Saf. 2005;31(7):406-13.

22. Paquette-Lamontagne N, McLean WM, Besse L, Cusson J. Evaluation of a new integrated discharge prescription form. Ann Pharmacother. 2001;35(7-8): 953-58.

23. Pal A, Babbott S, Wilkinson ST. Can the targeted use of a discharge pharmacist significantly decrease 30-day readmissions? Hosp Pharm. 2013;48(5):380-88

24. Iyer R, Coderre P, McKelvey T, et al. An employer-based, pharmacist intervention model for patients with type 2 diabetes. Am J Health Syst Pharm. 2010;67(4):312-16.

25. Barnett MJ, Frank J, Wehring H, et al. Analysis of pharmacist-provided medication therapy management (MTM) services in community pharmacies over 7 years. J Manag Care Pharm. 2009;15(1):18-31. Available at: http:// www.amcp.org/data/jmcp/018-031.pdf.

26. Wittayanukorn S, Westrick SC, Hansen RA, et al. Evaluation of medication therapy management services for patients with cardiovascular disease in a self-insured employer health plan. J Manag Care Pharm. 2013;19(5):385-95. Available at: http://www.amcp.org/WorkArea/DownloadAsset.aspx?id=16595.

27. Isetts BJ, Schondelmeyer SW, Artz MB, et al. Clinical and economic outcomes of medication therapy management services: the Minnesota experience. J Am Pharm Assoc (2003). 2008;48(2):203-11.

28. Kennedy J, Tuleu I, Mackay K. Unfilled prescriptions of medicare beneficiaries: prevalence, reasons, and types of medicines prescribed. J Manag Care Pharm. 2008;14(6):553-60. Available at: http://www.amcp.org/data/jmcp/ JMCPMaga_553-560.pdf.

29. Yang Y, Thumula V, Pace PF, Banahan BF 3rd, Wilkin NE, Lobb WB. Predictors of medication nonadherence among patients with diabetes in Medicare Part D programs: a retrospective cohort study. Clin Ther. 2009;31(10):2178-88. 
30. Garfield S, Clifford S, Eliasson L, Barber N, Willson A. Suitability of measures of self-reported medication adherence for routine clinical use: a systematic review. BMC Med Res Methodol. 2011;11(1):149.

31. Novick G. Is there a bias against telephone interviews in qualitative research? Res Nurs Health. 2008;31(4):391-98

32. Horne R, Weinman J, Hankins M. The beliefs about medicines questionnaire: the development and evaluation of a new method for assessing the cognitive representation of medication. Psychol Health. 1999;14(1):1-24.

33. Linacre JM. Optimizing rating scale category effectiveness. J Appl Meas. 2002;3(1):85-106.

34. Linacre JM. When does a gap between measures matter? Rasch Measurement Transactions. 2004;18(3):993. Available at: http://www.rasch. org/rmt/rmt183p.htm. Accessed March 15, 2015.

35. Bond TG, Fox CM. Applying the Rasch model: Fundamental Measurement in the Human Sciences. Mahwah, NJ: Lawrence Erlbaum; 2001.

36. Nau D. Executive update on medication quality measures in Medicare Part D plan ratings. Pharmacy Quality Alliance. 2013. Available at: http:// www.pqaalliance.org/images/uploads/files/2013\%20Update\%20n\%20 Medicare\%20Plan\%20Ratings.pdf. Accessed March 15, 2015.

37. Tudor CG. Enhancements to Medicare Part D patient safety reports and website. Memorandum. Centers for Medicare \& Medicaid Services. September 30, 2010. Available at: https://www.cms.gov/Medicare/ Prescription-Drug-Coverage/PrescriptionDrugCovContra/downloads/2010Pt SafetyReportEnhan_memo_093010.pdf. Accessed March 15, 2015.
38. Spence MM, Makarem AF, Reyes SL, et al. Evaluation of an outpatient pharmacy clinical services program on adherence and clinical outcomes among patients with diabetes and/or coronary artery disease. J Manag Care Pharm. 2014;20(10):1036-45. Available at: http://www.amcp.org/WorkArea/ DownloadAsset.aspx?id=18574.

39. Jackson TH, Bentley JP, McCaffrey DJ 3rd, Pace P, Holmes E, West-Strum D. Store and prescription characteristics associated with primary medication nonadherence. J Manag Care Pharm. 2014;20(8):824-32. Available at: http:// www.amcp.org/WorkArea/DownloadAsset.aspx?id=18372.

40. Baggarly SA, Kemp RJ, Wang X, Magoun AD. Factors associated with medication adherence and persistence of treatment for hypertension in a Medicaid population. Res Social Adm Pharm. 2014;10(6):e99-e112.

41. Leslie RS, Tirado B, Patel BV, Rein PJ. Evaluation of an integrated adherence program aimed to increase medicare part D Star rating measures. J Manag Care Pharm. 2014;20(12):1193-203. Available at: http://www.amcp. org/WorkArea/DownloadAsset.aspx?id=18840.

42. Academy of Managed Care Pharmacy; American Pharmacists Association. Medicare star ratings: stakeholder proceedings on community pharmacy and managed care partnerships in quality. J Am Pharm Assoc (2003). 2014;54(3):228-40. 


\section{APPENDIX Telephone Medication Adherence Questionnaire}

PART 1: Patient Information Verification

Hello! May I speak to <PATIENT (first and last name) $>$ ? My name is <INTERVIEWER NAME > and I'm calling on behalf of your Medicare Part D insurance provider, $<$ PLAN NAME $>$.

We reviewed your medicines and wanted to talk to you about a few things for research purposes. It should only take a couple minutes. Any time when I ask you something, if it makes you feel uncomfortable, please let me know.

Before we get started, I'd like to verify some information:

1. Verify you have the right member: *Patient First and Last Name is a Required Identifier.

2. What is your date of birth?

3. And can I verify your address?

4. If unable to verify $D O B$ or Address: I will need to verify your Member ID number or a drug name for one of your medications.

5. If unable to verify 3 points of identification, inform the member that it is required by HIPAA regulations. The Targeted Medication Review (TMR) may not be completed until the member's identification is verified. Tell them we will send them the information in the mail.

6. Do you manage your own medicines? (If no-find out caregiver information, get patient's permission to contact caregiver, and contact them. Verify patient's first and last name*, DOB \& Address (or Member ID number or prescription number or drug name) with caregiver. If yes-continue).

First Name Middle Initial Last Name

Date of Birth ___ Member ID

Triggering Drug___ PDC (\% days covered)

Caregiver's relationship (if applicable)

Part 2: Medication Adherence

Q1: For which medical conditions are you taking prescription medications?

$\square$ Don't remember (Do Not Read). Go to Question 2.

$\square$ Record open-ended answer. Go to Question 2.

Q2: What problems do you have obtaining your medicines from the pharmacy?

$\square$ Record open-ended answer. Go to Question 3.

Q3: Do you receive medications by mail?

Y Yes. Go to Question 4.

$\square$ No. Skip to Question 5.

$\square$ Don't Know. Skip to Question 5.

$\square$ Refused (Do Not Read). Skip to Question 5.

Q4: What problems do you have obtaining your medicines by mail?

Decord open-ended answer. Go to Question 5.

Q5: During the last three months were any medicines prescribed for you that you did not GET?

$\square$ Yes. Go to Question 6.

$\square$ No. Skip to Question 8

$\square$ Don't Know. Skip to Question 8.

Defused (Do Not Read). Skip to Question 8.

Q6: What are the names of the medicines you did not GET?

$\square$ Don't remember (Do Not Read). Go to Question 7.

$\square$ Record open-ended answer. If patient does not know the names, redirect to the conditions for which these medications were intended to treat Go to Question 7.

Q7: Why didn't you your GET medicines? (READ AS OPEN-ENDED STATEMENTS). Select all that apply.

$\square$ I think the medicine was NOT NECESSARY for the condition.

$\square$ I thought medicine COST too much.

$\square$ The medicine was NOT COVERED by my insurance or plan formulary.

$\square$ I didn't have TIME to get the medication.

$\square$ The pharmacy was not conveniently located

$\square$ The prescription was not available (OUT OF STOCK)

I had to wait a long time at the pharmacy.

I had to go multiple times to the pharmacy to get my medications. 
I couldn't get to the pharmacy.

$\square$ I was afraid of medicine reactions (SIDE EFFECTS)

$\square$ I have taken the medicine before and it gave me problems.

I I FELT BETTER so I didn't need medicine.

$\square$ I used samples.

I got a $\$ 4$ generic/paid cash.

$\square$ I borrowed some medication from a friend.

$\square$ I used an HERBAL TREATMENT

$\square$ I used an over the counter (OTC) medication instead.

I tried a HOME REMEDY.

D Other (please specify).

Q8: During the last three months were any medicines prescribed for you that you GOT BUT DID NOT USE?

$\square$ Yes. Go to Question 9.

No. Skip to Question 11.

$\square$ Don't Know. Skip to Question 11.

$\square$ Refused (Do Not Read). Skip to Question 11.

Q9: What are the names of the medicines you did NOT USE?

$\square$ Don't remember (Do Not Read). Go to Question 10.

Record open-ended answer. If patient does not know the names, redirect to the conditions for which these medications were intended to treat Go to Question 10.

Q10: Why didn't you USE your medicines? (READ AS OPEN-ENDED STATEMENTS). Select all that apply.

I think the medicine was NOT NECESSARY for the condition.

$\square$ I thought medicine COST too much.

I was afraid of medicine reactions (SIDE EFFECTS)

I have taken the medicine before and it GAVE ME PROBLEMS

$\square$ I FELT BETTER so I didn't need medicine.

$\square$ I used samples.

$\square$ I got a $\$ 4$ generic/paid cash.

$\square$ I borrowed some medication from a friend.

$\square$ I got some medication from another source.

$\square$ I used an over the counter (OTC) medication instead.

I tried a home remedy

I got the medication from Mexico/Canada.

$\square$ Other (please specify).

Q11: During the last three months were any medicines prescribed for you that you started using but STOPPED?

$\square$ Yes. Go to Question 12.

No. Skip to Question 14.

$\square$ Don't Know. Skip to Question 14.

$\square$ Refused (Do Not Read). Skip to Question 14.

Q12: What are the names of the medicines you started using but STOPPED?

Don't remember (Do Not Read). Go to Question 13.

Record open-ended answer. If patient does not know the names, redirect to the conditions for which these medications were intended to treat. Go to Question 13.

Q13: Why did you STOP your medicines? (READ AS OPEN-ENDED STATEMENTS). Select all that apply.

$\square$ I think the medicine was NOT NECESSARY for the condition.

$\square$ I thought medicine COST too much.

$\square$ I was afraid of medicine reactions (SIDE EFFECTS).

$\square$ I have taken the medicine before and it GAVE ME PROBLEMS.

$\square$ I FELT BETTER so I didn't need medicine.

$\square$ My PHYSICIAN SWITCHED the medicine.

$\square$ Other (please specify). 


\section{APPENDIX Telephone Medication Adherence Questionnaire (continued)}

Part 3: Beliefs About Medications

The next statements refer to beliefs about medicines. On a scale of 1 to 4 , with 1 being strongly disagree and 4 being strongly agree, please rate the following statements:

\begin{tabular}{|c|c|c|c|c|}
\hline Question & Strongly Disagree & Disagree & Agree & Strongly Agree \\
\hline Q14: I worry about taking medicines & $1 \square$ & $2 \square$ & $3 \square$ & $4 \square$ \\
\hline Q15: I can live without my medications & $1 \square$ & $2 \square$ & $3 \square$ & $4 \square$ \\
\hline Q16: I do not worry about the future problems of my medicines & $1 \square$ & $2 \square$ & $3 \square$ & $4 \square$ \\
\hline Q17: My medicines keep me healthy & $1 \square$ & $2 \square$ & $3 \square$ & $4 \square$ \\
\hline Q18: My medicines are easy to use & $1 \square$ & $2 \square$ & $3 \square$ & $4 \square$ \\
\hline
\end{tabular}

Part 4: Other Information Regarding Medications

Q19: What else regarding your medicines would you like to tell us?

$\square$ Record open-ended answer. Go to Question 20.

Part 5: Patient Demographic Information

Finally, we'd like to find out a little bit more about you. The following questions are related to your personal attributes.

Q20: What is your current marital status? (READ AS OPEN-ENDED STATEMENTS). Are you currently:
$\square$ Married
$\square$ Partnered
$\square$ Widowed
$\square$ Divorced
$\square$ Separated
$\square$ Never married
$\square$ Refused (Do Not Read)

Q21: What is the highest level of education you have completed?

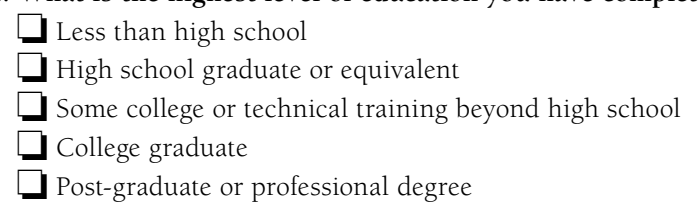

Q20: Which of the following best describes your current employment status? Are you currently:

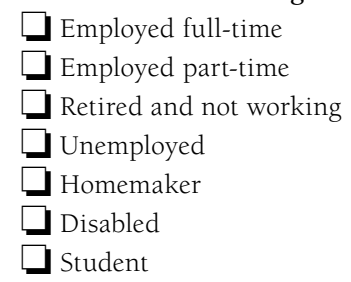

This concludes our survey. Thank you for your time and cooperation 